\title{
Long-term prognosis after acute anterior infarction with atrioventricular block
}

\author{
WILLIAM R. GINKS, RICHARD SUTTON, ${ }^{1}$ WINSTON OH \\ AND AUBREY LEATHAM
}

From St. George's Hospital, London; and the National Heart Hospital, London

The purpose of this study was to evaluate the need for permanent pacing in patients who have survived the effects of anterior myocardial infarction with complete heart block and have returned to sinus rhythm but who are left with impairment of intraventricular conduction. We have reviewed 52 patients with complete heart block complicating recent anterior myocardial infarction. Temporary pacing was instituted in all patients. There were 25 hospital survivors who were followed for an average of 49 months. Long-term pacing was established in 4 patients. Of the 21 patients in sinus rhythm, 14 had partial bilateral bundle-branch block with either right bundle-branch block and left anterior hemiblock or right bundle-branch block and left posterior hemiblock; at the end of the follow-up period, 10 of these 14 were alive and well. Furthermore, permanent pacing failed to prevent sudden death in 2 patients. At the present time, therefore, we conclude that longterm pacing is not justified in patients, otherwise asymptomatic, with partial bilateral bundle-branch block persisting after transient complete heart block in anterior myocardial infarction.

Survivors from acute anterior infarction complicated by complete heart block usually return to sinus rhythm after a few days, but most are left with electrocardiographic evidence of bifascicular block, sometimes with additional prolongation of the PR interval. In view of the fact that atrioventricular conduction may be precarious and that coronary disease is by nature progressive, there is a case for installation of a demand pacing system. On the other hand, competition or excessive power of stimulation could produce fatal ventricular fibrillation. Furthermore, endocardial potentials necessary for appropriate function of the demand pacemaker may be reduced in these patients who have almost invariably had a very large infarct. For this reason, we have been reluctant to use a pacemaker in such cases and now give the results of a follow-up averaging 49 months in a group of 25 patients.

\section{Methods}

The medical records and standard 12-lead electrocardiograms of 52 patients admitted to our care in the 10-year period up to December 1973 were

${ }^{1}$ Present address: Westminster Hospital, Dean Ryle Street, London SW1P 2AP.

Received for publication 21 July 1976 reviewed. All had been referred with recent anterior myocardial infarction complicated by the development of complete heart block. It was not known whether there was pre-existing fascicular block before infarction. In 2 patients (Cases 3 and 6) a narrow QRS in the presence of complete heart block suggested proximal atrioventricular block. In all other patients the level of the block was considered to be distal in site because of the slow rate of the escape pacemaker and a QRS width of at least $0 \cdot 12 \mathrm{~s}$. All patients needed temporary pacing.

The diagnosis of acute myocardial infarction was established by a typical history accompanied by characteristic enzyme rises and the development of pathological $Q$ waves accompanied by ST segment and $T$ wave changes in the anterior chest leads. Bundle-branch block was defined according to the criteria of Goldman (1967) and the criteria for hemiblock were those of Rosenbaum (1970). Partial bilateral bundle-branch block was defined as right bundle-branch block and left anterior hemiblock or right bundle-branch block and left posterior hemiblock.

The usual hospital stay was at least 3 weeks and follow-up observations were obtained in all patients. $\mathrm{His}$ bundle electrograms were recorded in 8 patients after return to sinus rhythm, using the technique described by Scherlag et al. (1969). 


\section{Results}

Of the 52 patients 27 died in hospital, giving a mortality of 52 per cent. The majority of deaths in hospital were the result of myocardial failure. Four patients developed ventricular fibrillation despite pacing, 1 patient had a further infarct, and 1 patient who had returned to sinus rhythm with right bundle-branch block and left anterior hemiblock within 24 hours of infarction died suddenly 2 weeks after admission (Table 1).

The 25 survivors, with ages ranging from 36 to 78 years (mean 60 years), who left hospital have been followed to death or for a period of time ranging from 21 to 84 months and averaging 49 months. Only 1 of the 25 survivors (Case 25, Table 2) was still in complete heart block when ready for discharge from hospital and indisputably required a permanent pacing system. Of the 24 who had returned to sinus rhythm only 2 had a normal PR interval and a normal QRS complex (Cases 1 and 2). In 5 patients there was both prolongation of the PR interval (more than $0.20 \mathrm{~s}$ ) and of the QRS complex with partial bilateral bundle-branch block, indicatthe possibility of return to complete heart block. In 2 of these patients (Cases 14 and 19) an attempt was made to install a permanent demand pacing system but, because endocardial potentials were considered too low, it was thought safer not to pace them; both
Table 1 Initial outcome in 52 patients with acute anterior myocardial infarction with complete heart block

\begin{tabular}{lrr}
\hline Deaths in hospital & 27 \\
Myocardial failure & 21 & \\
Ventricular fibrillation & 4 & \\
Further infarction & 1 & \\
Sudden death & 1 & \\
Survivors & & 25 \\
Atrioventricular block (paced) & 1 & \\
Sinus rhythm (1 paced) & 24 & \\
\hline
\end{tabular}

are still in sinus rhythm 47 and 49 months later. In a third patient (Case 20), with normal endocardial potentials, the continued use of procainamide for ectopic beats in the presence of partial bilateral bundle-branch block led us to install a demand pacing system, but despite this he died suddenly 18 months later. In 2 patients, complete heart block without syncopal attacks developed 4 months and 24 months later and pacemakers were inserted; 1 of these (Case 3) had had a long PR interval and a normal QRS and was well at 53 months, but the other (Case 5) who had had a long PR interval, left bundle-branch block, and heart failure, died suddenly at 3 years.

Thus, of the 16 patients alive and well at the end of the follow-up period, only 2 with complete heart block were being paced. The remainder were in sinus rhythm; 10 had partial bilateral bundle-

Table 2 Electrocardiographic findings after recovery from infarction and follow-up in the 25 survivors

\begin{tabular}{|c|c|c|c|c|c|c|c|}
\hline Case No. & Age & and sex & $P R$ interval $(s)$ & $Q R S$ & $H V(s)$ & $\begin{array}{l}\text { Follow-up } \\
\text { period (mth) }\end{array}$ & Outcome \\
\hline $\begin{array}{r}1 \\
2 \\
3 \\
4 \\
5 \\
6 \\
7 \\
8 \\
9 \\
10 \\
11 \\
12 \\
13 \\
14 \\
15 \\
16 \\
17 \\
18 \\
19 \\
20 \\
21 \\
22 \\
23\end{array}$ & $\begin{array}{l}63 \\
49 \\
68 \\
71 \\
65 \\
57 \\
55 \\
66 \\
61 \\
65 \\
64 \\
48 \\
78 \\
59 \\
64 \\
61 \\
47 \\
69 \\
66 \\
71 \\
56 \\
60 \\
69 \\
36 \\
59\end{array}$ & 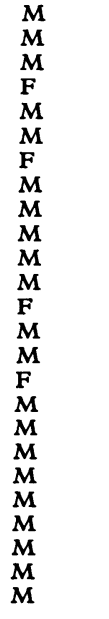 & $\begin{array}{l}0 \cdot 16 \\
0 \cdot 18 \\
0 \cdot 26 \\
0 \cdot 18 \\
0 \cdot 22 \\
0 \cdot 28 \\
0 \cdot 14 \\
0 \cdot 14 \\
0 \cdot 18 \\
0 \cdot 16 \\
0 \cdot 14 \\
0 \cdot 16 \\
0 \cdot 16 \\
0 \cdot 21 \\
0 \cdot 16 \\
0 \cdot 12 \\
0 \cdot 20 \\
0 \cdot 20 \\
0 \cdot 24 \\
0 \cdot 24 \star \\
0 \cdot 21 \\
0 \cdot 16 \\
0 \cdot 14 \\
0 \cdot 22 \\
\mathrm{CHB}\end{array}$ & $\begin{array}{l}\text { Normal } \\
\text { Normal } \\
\text { Normal } \\
\text { LBBB } \\
\text { LBBB } \\
\text { LAH } \\
\text { LAH } \\
\text { LPH } \\
\text { RBBB } \\
\text { RBBB + LAH } \\
\text { RBBB + LAH } \\
\text { RBBB + LAH } \\
\text { RBBB + LAH } \\
\text { RBBB + LAH } \\
\text { RBBB + LAH } \\
\text { RBBB + LAH } \\
\text { RBBB + LAH } \\
\text { RBBB + LAH } \\
\text { RBBB + LAH } \\
\text { RBBB + LAH } \\
\text { RBBB + LPH } \\
\text { RBBB + LPH } \\
\text { RBBB + LPH } \\
\text { RBBB + LPH } \\
\text { LBBB }\end{array}$ & $\begin{array}{l}- \\
- \\
- \\
- \\
- \\
\bar{Z} \\
0.045 \\
0.040 \\
- \\
\overline{0} \\
-070 \\
- \\
- \\
0.070 \\
0.070 \\
0.065 \\
0.065 \\
0.040 \\
- \\
- \\
-\end{array}$ & $\begin{array}{r}84 \\
71 \\
53 \\
3 \\
36 \\
43 \\
38 \\
39 \\
55 \\
65 \\
13 \\
31 \\
36 \\
47 \\
62 \\
3 \\
17 \\
23 \\
49 \\
18 \\
55 \\
21 \\
41 \\
34 \\
57\end{array}$ & $\begin{array}{l}\text { Sinus rhythm; alive } \\
\text { Sinus rhythm; alive } \\
\text { CHB; paced; alive } \\
\text { Sinus rhythm; death } \\
\text { CHB, paced; sudden death } \\
\text { Sinus rhythm; death } \\
\text { Sinus rhythm; sudden death } \\
\text { Sinus rhythm; alive } \\
\text { Sinus rhythm; alive } \\
\text { Sinus rhythm; alive } \\
\text { Sinus rhythm; sudden death } \\
\text { Sinus rhythm; alive } \\
\text { Sinus rhythm; alive } \\
\text { Sinus rhythm; alive } \\
\text { Sinus rhythm; alive } \\
\text { Sinus rhythm; death } \\
\text { Sinus rhythm; death } \\
\text { Sinus rhythm; alive } \\
\text { Sinus rhythm; alive } \\
\text { Sinus rhythm; paced; sudden death } \\
\text { Sinus rhythm; alive } \\
\text { Sinus rhythm; alive } \\
\text { Sinus rhythm; alive } \\
\text { Sinus rhythm; sudden death } \\
\text { CHB; paced; alive }\end{array}$ \\
\hline
\end{tabular}

LBBB, left bundle-branch block; LAH, left anterior hemiblock; LPH, left posterior hemiblock; RBBB, right bundle-branch block; CHB, complete heart block.

^Patients paced before discharge from hospital. 
branch block, and 3 of these also had a prolonged PR interval.

Of the 9 late deaths (Table 3), 4 were attributable to chronic irreversible heart failure or further infarction. The other 5 were sudden and might have been caused by ventricular standstill. Of the 5,2 had pacemakers and normal in vivo function of the pacemaker had been confirmed in both patients within 2 months of death; furthermore, both the pacing electrode and pulse generator were satisfactory at necropsy. There were 3 patients who might have benefited from a pacemaker: 1 (Case 24) was in chronic heart failure, but in the 2 others a pacemaker might have been life-saving. Selection of these patients for prophylactic pacing would have presented difficulties since one (Case 7) was in sinus rhythm with unifascicular block, and the other (Case 11) was in steady sinus rhythm with a PR of $0.14 \mathrm{~s}$ and an $\mathrm{HV}$ of $0.04 \mathrm{~s}$, though he did have right bundle-branch block with left axis deviation.

\section{Discussion}

The mortality of acute anterior infarction with complete atrioventricular block is reported to be approximately 80 per cent and results from the large size of an infarct, large enough to involve both right and left bundle-branch conducting systems (Stock, 1969; Norris et al., 1972). The lower mortality $(52 \%)$ in the group reported here may be the result of some selection of cases by their ability to survive transfer from another hospital. On the other hand, special precautions taken with the pacing technique probably played an important part, as these patients are particularly vulnerable to arrhythmias. Suppressant drugs were given before the electrode was passed through the tricuspid valve and a close watch was maintained for the low endo- cardial potentials which are likely to occur in these patients with large infarcts and heart failure, and which may result in failure of inhibition of the demand pacing system, causing inappropriate stimulation with its danger of ventricular fibrillation (Chatterjee et al., 1969). Thresholds were measured daily and the pacing voltage was kept to less than twice the threshold voltage. In some borderline cases overdrive fixed rate pacing was preferred to demand pacing. Demand pacing systems were not withdrawn until 7 days after return to sinus rhythm with the final 24 hours on a pacing counter to detect transient return of block. Despite these precautions, 4 patients died unexpectedly of ventricular fibrillation late in their hospital stay.

The long-term follow-up in this series confirms the high late mortality in survivors from complete heart block complicating anterior myocardial infarction. Sudden death, however, occurred in only 2 of the 14 non-paced patients with partial bilateral bundle-branch block, and our experience contrasts with that of Atkins and colleagues who reported sudden death within 6 months of hospital discharge in 5 of 6 unpaced patients who had partial bilateral bundle-branch block after anterior infarction with transient complete heart block (Atkins et al., 1973). It is interesting to note that the same authors also reported a group of 12 patients in sinus rhythm with right bundle-branch block and left anterior hemiblock who were permanently paced; 6 died ( 2 suddenly) within 15 months (Ritter et al., 1975).

A review of the published reports shows that the persistence of conduction defects after acute myocardial infarction is not a reliable guide to the risk of late sudden death. In the Coronary Drug Project, 13 patients with partial bilateral bundle-branch block after myocardial infarction were followed for

Table 3 Electrocardiographic findings in 9 patients dying after discharge from hospital

\begin{tabular}{|c|c|c|c|c|}
\hline Case No. & $P R$ interval & Type of conduction abnormality & $\begin{array}{l}\text { Interval between } \\
\text { infarct and death (mth) }\end{array}$ & Other features \\
\hline \multicolumn{5}{|c|}{ Sudden death } \\
\hline 5 & 0.22 & $\begin{array}{l}\text { LBBB } \rightarrow \text { CHB } \\
\text { Permanent pacing }\end{array}$ & 36 & Dizziness + heart failure before pacing \\
\hline 7 & $0 \cdot 14$ & LAH & 38 & Symptom free \\
\hline 11 & $0 \cdot 14$ & RBBB + LAH (HV 40 ms) & 13 & Symptom free \\
\hline 20 & $0 \cdot 24$ & $\begin{array}{l}\text { RBBB + LAH (HV } 65 \mathrm{~ms} \text { ) } \\
\text { Antiarrhythmic therapy } \\
\text { Permanent pacing }\end{array}$ & 18 & $\begin{array}{l}\text { Necropsy showed fresh occlusion of right coronary } \\
\text { artery }\end{array}$ \\
\hline \multicolumn{2}{|c|}{ Further infarct } & $\mathbf{R B B B}+\mathbf{L P H}$ & 34 & Heart failure \\
\hline $\begin{array}{l}16 \\
\text { Heart failu }\end{array}$ & $0 \cdot 12$ & $\mathbf{R B B B}+\mathbf{L A H}$ & 3 & \\
\hline 4 & $0 \cdot 18$ & LBBB & 3 & \\
\hline 6 & $0 \cdot 28$ & LAH & 43 & \\
\hline 17 & $0 \cdot 20$ & RBBB + LAH & 17 & \\
\hline
\end{tabular}


a period of 3 years without mortality (Coronary Drug Project Research Group, 1972). Nimetz et al. (1973) reviewed a group of 71 patients with right or left bundle-branch block complicating acute myocardial infarction and found that the presence or absence of atrioventricular block failed to distinguish candidates for late sudden death: in 30 patients with associated second or third degree atrioventricular block there were 18 hospital and 3 late ( 2 sudden) deaths; by contrast, in the 41 patients without atrioventricular block there were 5 hospital and 14 late deaths (8 sudden) (Nimetz et al., 1973). More recently, Rosen and his colleagues recorded intracardiac electrocardiograms in a large but heterogeneous group of patients with right bundle-branch block and left anterior hemiblock and found no significant difference in the incidence of sudden death between those with prolongation of the HV interval and those in whom this measurement was normal (Denes et al., 1975).

The mechanism of sudden death in such cases remains speculative. It has been implied that patients with partial bilateral bundle-branch block are at risk from death as a result of complete heart block and asystole. Such patients, however, have advanced coronary artery disease and sudden death may well be the result of ventricular fibrillation during an ischaemic attack. Watanabe has reported a high incidence of ventricular arrhythmias in patients with intraventricular conduction defects (Watanabe et al., 1973). Hasanain et al (1973) have reported that the majority of patients with bifascicular block have premature ventricular beats and occasional ventricular tachycardia when exercised on the treadmill. The fact that sudden death occurred in 2 of the 4 patients with permanent pacing systems in our series indicates the potential risk of ventricular fibrillation, possibly as a result of inappropriate stimulation by the pacemaker during acute myocardial ischaemia or infarction.

In conclusion, a high early and late mortality is to be expected after anterior infarction complicated by complete heart block because of the extent of coronary disease likely to be present and the large area of myocardial damage. It is doubtful, however, whether the overall late mortality is significantly different from that in any group of patients with severe coronary artery disease. It is, therefore, extremely difficult to judge the part played by irreversible damage to conducting tissue. From the evidence available we conclude that there is no justification at present for the routine insertion of a prophylactic pacing system in patients, otherwise asymptomatic, who have returned to reliable sinus rhythm after anterior myocardial infarction with complete heart block, even in those with persisting partial bilateral bundle-branch block.

\section{References}

Atkins, J. M., Leshin, S. J., Blomquist, C. G., and Mullins, C. B. (1973). Ventricular conduction blocks and sudden death in acute myocardial infarction. New England fournal of Medicine, 288, 281-287.

Chatterjee, K., Harris, A., and Leatham, A. (1969). The risk of pacing after infarction and current recommendations. Lancet, 2, 1061-1064.

Coronary Drug Project Research Group (1972). The prognostic importance of the electrocardiogram after myocardial infarction. Annals of Internal Medicine, 77, 677-689.

Denes, P., Dhingra, R., Wu, D., Chuquimia, R., Amat-YLeon, F., Wyndham, C., and Rosen, K. M. (1975). H-V interval in patients with bifascicular block (right bundlebranch block and left anterior hemiblock). American Fournal of Cardiology, 35, 23-29.

Goldman, M. J. (1967). Principles of Clinical Electrocardiography, 6th ed. Lange Medical Publications, Los Altos, California.

Hasanain, J., Ashley, W. W., Denes, P., Dhingra, R., and Rosen, K. (1973). Effect of exercise on cardiac conduction in patients with bifascicular block. Circulation, 47-48, Suppl. IV, IV-175.

Nimetz, A. A., Shubrooks, S. J., Hutter, A. M., and De Sanctis, R. W. (1973). Bundle-branch block complicating acute myocardial infarction. Circulation, 47-48, Suppl. IV, IV-122.

Norris, R. M., Mercer, C. J., and Croxson, M. S. (1972). Conduction disturbances due to anteroseptal myocardial infarction and their treatment by endocardial pacing. American Heart fournal, 84, 560-566.

Ritter, W. S., Atkins, J. M., Blomquist, C. G., and Mullins, C. B. (1975). Permanent pacing in patients with transient trifascicular block during acute myocardial infarction: long term prognosis. Circulation, 52, Suppl. II, II-13.

Rosenbaum, M. B. (1970). The hemiblocks: diagnostic criteria and clinical significance. Modern Concepts of Cardiovascular Disease, 39, 141-146.

Scherlag, B. J., Lau, S. H., Helfant, R. H., Berkowitz, W. D., Stein, E., and Damato, A. N. (1969). Catheter technique for recording His bundle activity in man. Circulation, 39, 13-18.

Stock, J. P. (1969). Diagnosis and Treatment of Cardiac Arrhythmias. Butterworth, London.

Watanabe, Y., Pamintuan, J. C., and Dreifus, L. S. (1973). Role of intraventricular conduction disturbances in ventricular premature systoles. American fournal of Cardiology, 32, 188-195.

Requests for reprints to Dr. W. R. Ginks, Cardiac Department, St. George's Hospital, Hyde Park Corner, London SW1X 7EZ. 